\title{
SEARCH FOR NEUTRINO OSCILLATION AT BUGEY
}

\author{
J.F. Cavaignac, Y. Declais ${ }^{\star}$, A. Hoummada, H. de Kerret, D.H. Koang, \\ H. Pessard, J.M. Thenard and B. Vignon \\ Institut des Sciences Nucléaires, IN2P3, 38026 Grenoble Cedex, France \\ ${ }^{\star}$ LAPP, IN2P3, B.P. 909, 74019 Annecy le Vieux Cedex, France
}

Rêsumé - Le flux des ve produits par 1e coeur d'un réacteur PWR de_Bugey a étê utilisé pour rechercher les oscillations neutrino à l'aide de la réaction $\bar{v}_{e}+p \rightarrow e^{+}+n$. Les mesures ont été effectuées à 2 distances : $13,5 \mathrm{~m}$ et $18,5 \mathrm{~m}$. Environ 50 o00 évènements neutrino ont été détectés à la première position et 25000 évènements à la seconde position. L'analyse des résultats est en cours d'achèvement.

Abstract - The high fIux of low energy $\bar{v}_{\text {e }}$ produced by the core of a PWR reactor of Bugey power plant has been used to search for evidence of neutrino oscillations through the inverse beta decay reaction $\bar{v}_{e}+p \rightarrow e^{+}+n$.

Measurements have been performed at two distances $(13.5$ and $18.5 \mathrm{~m})$. About $50000 \bar{v}_{\mathrm{e}}$ events have been collected at the first position and $25000 \bar{v}_{\mathrm{e}}$ events at the second one. Data analysis is almost completed.

\section{Introduction}

The high flux of 10w energy $\bar{v}_{\text {e }}$ produced by the core of a PWR reactor $\left(2785 \mathrm{MW}_{\mathrm{th}}\right)$ of Bugey power plant is used to search for evidence of neutrino oscillations through the inverse beta decay reaction $\bar{v}_{\mathrm{e}}+\mathrm{p} \rightarrow \mathrm{e}^{+}+n$. The previous experiment at ILL-Grenoble, [ref.1], has shown that oscillations if they exist in the eV range would happen only with a small mixing angle. To reduce both the statistical and systematical uncertainties, we have undertaken a two distance measurement taking avantage of the high $v_{e}$ flux available at the Bugey basement $\left(2.10^{-13} v_{e} / \mathrm{cm}^{2} \mathrm{sec}\right.$.

at $13.5 \mathrm{~m}$ and $10^{13} \nu_{\mathrm{e}} / \mathrm{cm}^{2} \mathrm{sec}$ at $18.5 \mathrm{~m}$; as compared to the $10^{12} \bar{v}_{\mathrm{e}} / \mathrm{cm}^{2} \mathrm{sec}$ at ILL.).

\section{Experimental set-up}

The letector, similar to the one previously used at the ILL reactor ref.1, consists of five planes of six target cells filled with liquid scintillator (321 1iters of iE: 2350 ), alternated with four 3He wire-chambers. The liquid scintillator serves as proton target, prompt positron detector and neutron moderator. The thermalized

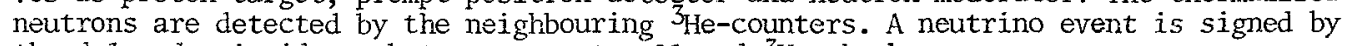
the delayed coincidence between target cell and $3_{\mathrm{He}}$ chamber.

The detector is completely surrounded by $7 \mathrm{~cm}$ of low activity lead, $10 \mathrm{~cm}$ of veto counters filled with liquid scintillator, $25 \mathrm{~cm}$ of bored water and $10 \mathrm{~cm}$ of lead. For both positions, the same designs of shielding are used and the anount of material overhead is more than $25 \mathrm{~cm}$ of water equivalent, reducing the muon flux by more than a factor of 5 . In addition, the remaining fast neutrons are rejected by the pulse shape discrimination technique. Background was measured for both positions during the ammual shut-down of the reactor in March-April 1983 and no significant reactor associated accidental background was found. Stabilities of apparatus were controlled on line and have been frequently checked using ganma and neutron sources. 
The detector efficiency mapping using calibrated $\mathrm{Sb}(\mathrm{Be})$ neutron source have been achived in July 1983. About 50 O00 neutrino-events have been detected at $13.5 \mathrm{~m}$ and 25000 at $18.5 \mathrm{~m}$.

The data analysis is almost completed. The final results on the oscillation of neutrinos from the present experiment could be soon presented.

The aim of our present experiment is to measured with high statistics the neutrino spectrum at two distances and thus to reduce drastically both the systematical $(\leqslant 3 \%)$ and statistical errors. Assuming a.simple two state oscillation model, $\left(v_{e} \rightarrow v_{x}\right)$, our experiment is most sensitive in the range of $\Delta \mathrm{m}^{2}$ from few $\mathrm{eV}^{2}$ down to $0.03 \mathrm{eV}$ and a 1imit of mixing angle $\sin ^{2} 2 \theta \leqslant 0.07$ could be attained.

Ref. 1 : Ca1tech, ILL-ISN Grenoble, Munich collaboration, H. Kwon et a1 Phys. Rev. D. 24 (1981) 1097. 